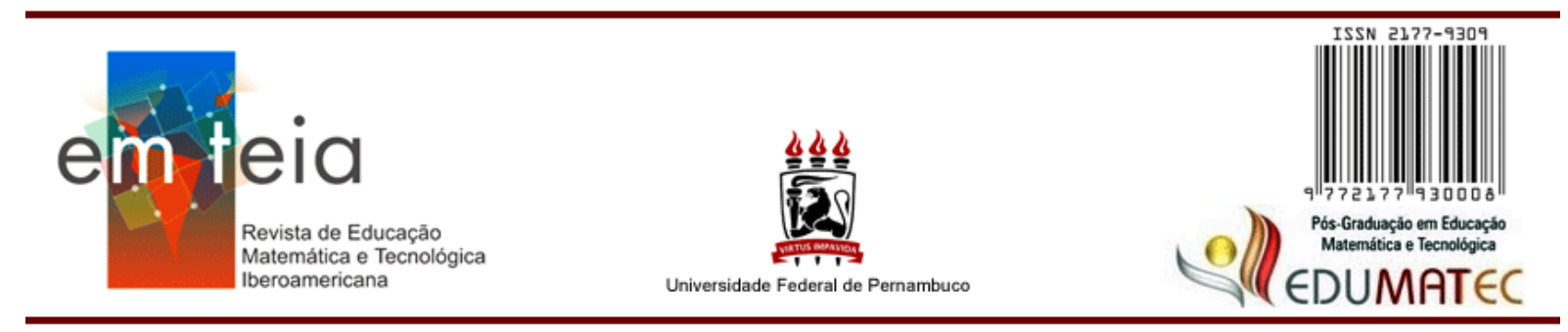

\title{
CENÁRIOS E DESAFIOS DA EDUCAÇÃO MATEMÁTICA: DA INVESTIGAÇÃO À SALA DE AULA
}

\author{
Gilda Guimarães \\ Universidade Federal de Pernambuco \\ gilda.lguimaraes@gmail.com \\ Rosinalda Teles \\ Universidade Federal de Pernambuco \\ rosinaldateles@yahoo.com.br
}

Marilene Rosa dos Santos

Universidade de Pernambuco rosa.marilene@gmail.com

\section{Resumo}

Este artigo teve por objetivo analisar a produção científica apresentada no VII Encontro Pernambucano de Educação Matemática (EPEM), evidenciando o cenário atual e os desafios que ainda precisam ser enfrentados pela Educação Matemática. Para isso, realizamos um estado da arte relativo aos trabalhos publicados nos Anais desse evento. A partir dos eixos temáticos identificamos a filiação institucional dos autores e suas formações acadêmicas, bem como uma síntese dos objetivos, sujeitos envolvidos, bases teóricas utilizadas, métodos e principais resultados. Evidenciamos um cenário promissor em relação à participação de graduandos, professores da educação básica e pesquisadores de diversas instituições e áreas do conhecimento. Os desafios mais relevantes são oportunizar estudos que possam contribuir com professores e alunos da Educação Infantil e comunidades indígenas e quilombolas, refletir sobre a necessidade de estudos em áreas ainda pouco investigadas como álgebra, estatística e probabilidade nos diversos níveis de ensino.

Palavras-Chave: Estado da arte. Encontro Pernambucano de Educação Matemática. Formação de professor. Pesquisa.

\begin{abstract}
This paper aimed to analyze the scientific production presented at the VII ${ }^{\text {th }}$ Meeting of Mathematics Education of Pernambuco (EPEM), highlighting the current scenario and the challenges that still need to be faced by Mathematics Education. For this, we carried out a state of the art related to the papers published in the proceedings of this event. From the thematic axes we identified the institutional affiliation of the authors and their academic formations, as well as a synthesis of the objectives, subjects, theoretical bases, methods and main results. We show a promising scenario regarding the participation of undergraduates, teachers of basic education and researchers from various institutions and areas of knowledge. The most relevant challenges are to provide studies that may bring contributions to teachers and students of Early Childhood Education and indigenous and quilombola communities, to reflect on the need for studies in areas that are still underdeveloped, such as algebra, statistics and probability at different levels of education.
\end{abstract}

Keywords: State of the art, Meeting of Mathematics Education of Pernambuco, Teacher training, Research. 


\section{Introdução}

Atualmente em Pernambuco existem vários programas de pós-graduação stricto sensu que realizam estudos na área de Educação Matemática. Entre eles, o Programa de PósGraduação em Educação Matemática e Tecnológica (Edumatec), em Educação (PPGE) e em Psicologia Cognitiva (PPGPG), todos da UFPE/Campus Recife. Também temos Educação em Ciências e Matemática e o Programa Educação Contemporânea, ambos da UFPE/Caruaru. Nesse panorama, temos ainda o Programa de Pós-Graduação no Ensino de Ciências e Matemática - UFRPE /Recife.

Neste cenário, vários especialistas, mestres e doutores formados no próprio estado, além dos professores que atuam na escola básica e estudantes de diversas graduações, retomam a realização de um evento abrangente que possibilitasse a troca de experiências e pesquisas que pudessem subsidiar o trabalho a ser desenvolvido por professores dos diversos níveis de ensino relacionados à aprendizagem de conceitos matemáticos.

Esse artigo tem como objetivo apresentar uma síntese da produção científica do VII EPEM em 2017, evidenciando os cenários atuais e indicativos em relação aos desafios que ainda precisam ser enfrentados pela Educação Matemática em Pernambuco e no Brasil.

De acordo com Vosgerau e Romanowski (2014), esse estudo se configura como um estado da arte, uma vez que busca identificar temáticas recorrentes e apontando novas perspectivas, consolidando uma área de conhecimento. Assim, são analisadas as produções bibliográficas de um evento científico evidenciando novas ideias, métodos, subtemas que têm recebido maior ou menor ênfase na literatura selecionada. Não nos restringimos nesse estudo a identificar a produção, mas analisá-la, categorizá-la revelando os múltiplos enfoques e perspectivas. Nesse sentido, concordamos com Ferreira (2002, p. 01) quando reflete que o estado da arte é um tipo de pesquisa de caráter bibliográfico que

parece trazer em comum o desafio de mapear e de discutir uma certa produção acadêmica em diferentes campos do conhecimento, tentando responder que aspectos e dimensões vêm sendo destacados e privilegiados em diferentes épocas e lugares, de que formas e em que condições têm sido produzidas certas dissertações de mestrado, teses de doutorado, publicações em periódicos e comunicações em anais de congressos e de seminários. Também são reconhecidas por realizarem uma metodologia de caráter inventariante e descritivo da produção acadêmica e científica sobre o tema que busca investigar, à luz de categorias e facetas que se caracterizam enquanto tais em cada trabalho e no conjunto deles, sob os quais o fenômeno passa a ser analisado. 
Como argumentam Noronha e Ferreira (2000), nesse tipo de estudo são analisadas as produções bibliográficas sobre um tópico específico, evidenciando novas ideias, métodos, subtemas que têm recebido maior ou menor ênfase na literatura selecionada.

Um estado do conhecimento ou estado da arte não se restringe a identificar a produção, mas analisá-la, categorizá-la e revelar os múltiplos enfoques e perspectivas. É uma possibilidade de perceber discursos semelhantes, descontínuos ou contraditórios.

Fiorentini (2002) realizou um mapeamento do GT de Educação Matemática da Associação Nacional de Pós-Graduação e Pesquisa em Educação - Anped, entre 1998 e 2001, o qual destacava a Universidade Federal de Pernambuco (UFPE) em primeiro lugar pelo número de trabalhos apresentados, evidenciando a importância dessa instituição para a área. Entretanto, o autor ressalta que havia poucos trabalhos sobre a prática dos professores, o que seria desejável.

Guimarães e Pessoa (2014) realizaram o estado da arte dos artigos apresentados em comunicações orais no Grupo de Trabalho de Educação Matemática dos EPENN (Encontro de Pesquisa em Educação do Norte e Nordeste) realizados em 2007, 2009 e 2011. As autoras observaram um grande número de trabalhos sobre conhecimento de alunos e formação de professores em diferentes níveis de escolaridade, entretanto, ressaltam que há uma ausência de explicitação das metodologias do processo de investigação realizado, como já havia sido observado por Godino, Carrillo, Castro, Lacasta, Muñoz-Catalán e Wilhelmi (2012) em trabalhos espanhóis. Além disso, as autoras chamam atenção para o grande número de trabalhos que investigam dificuldades de alunos e professores em detrimento de estudos que investiguem práticas de ensino que levem à aprendizagem.

Dessa forma, parece que tanto no Brasil como na Espanha há uma necessidade de pesquisas que subsidiem práticas eficientes de ensino aprendizagem em sala de aula.

Barbosa (2017) realizou uma revisão das abordagens teóricas e metodológicas que circulam na Educação Matemática, a partir de aproximações e distanciamentos dos textos aprovados para o Trabalho Encomendado do GT19 da Anped, numa perspectiva apresentada por Rich (1972). O autor chama atenção para a complexidade das categorizações de metodologias e abordagens teóricas, observando que uma "mesma abordagem metodológica pode ser utilizada de diferentes formas, de modo que sua particularização depende da abordagem teórica adotada em cada pesquisa" (p. 31). Entretanto, ressalta que "as articulações metodológicas e suas singularizações devem igualmente serem vistas em termos de coerência com o solo teórico da pesquisa" (p. 35). 
O estado da arte na Educação Matemática realizado por Fiorentini, Passos e Lima (2016) que analisou as 858 dissertações e teses envolvendo dezenas de pesquisadores das cinco regiões brasileiras é uma enorme contribuição à área de Educação Matemática. Entre as várias conclusões apresentadas, os autores afirmam que nas pesquisas sobre professores que ensinam Matemática - PEM poucos justificam a escolha da abordagem metodológica mediante o objeto de estudo e existe, ainda, uma problemática em relação a pesquisas que sequer identificam a abordagem utilizada. Esses resultados nos levam a pensar sobre as implicações nas disciplinas sobre metodologia de pesquisa. Os autores observaram que predominam estudos de natureza empírica. Porém, chamam atenção para um problema que vem sendo levantado na área sobre o que é uma pesquisa teórica, bibliográfica ou documental, uma vez que em muitos casos os autores fazem um levantamento bibliográfico para a constituição do referencial teórico das pesquisas de campo e denominam de pesquisa teórica.

$\mathrm{Na}$ região Nordeste, $72 \%$ das pesquisas referem-se a estudos de caso ou etnográficos/participantes. Entretanto, os autores questionam se de fato essas pesquisas podem ser consideradas estudos de caso, pois não é qualquer contexto de pesquisa que pode ser caracterizado como um estudo de caso, uma vez que o estudo de caso se aplica quando o pesquisador tem interesse em investigar um caso particular, buscando uma definição clara dos aspectos característicos fundamentais do caso e o fato de este acrescentar conhecimento ao conhecimento já existente.

A entrevista foi o instrumento metodológico mais utilizado pelos pesquisadores. Há também um número significativo de pesquisas que utilizam observações e registros de aulas que são pesquisas realizadas nas escolas, em salas de aulas ou em grupos de trabalho. $\mathrm{O}$ maior percentual de pesquisas relaciona-se a investigar a formação inicial dos professores envolvendo saberes, crenças e projetos. Uma tendência que provavelmente se apresente como emergente é a história de professores que ensinam Matemática ou história da formação do PEM.

Assim, esse artigo tem como objetivo realizar o estado da arte do VII Encontro Pernambucano de Educação Matemática - EPEM, apresentando uma síntese da produção científica, evidenciando os cenários atuais e indicativos em relação aos desafios que ainda precisam ser enfrentados pela Educação Matemática em Pernambuco e no Brasil.

\section{Método}

O VII EPEM foi realizado em Garanhuns, cidade do agreste pernambucano, de 2 a 4 de novembro de 2017. Participaram do mesmo 1240 (um mil duzentas e quarenta) pessoas, sendo 
350 (trezentos e cinquenta) professores que atuam no Ensino Fundamental e Médio, 160 (cento e sessenta) professores que atuam no Ensino Superior, 600 (seiscentos) estudantes de graduação e 130 (cento e trinta) estudantes de pós-graduação, configurando-se, assim, como um espaço de troca entre escola básica e universidade.

A participação dos professores, em alguns casos financiada pelas secretarias de educação municipais, potencializou aspectos da formação continuada em serviço. Por outro lado, a supremacia da participação de estudantes de graduação destaca a importância do evento para formação inicial de Licenciandos em Matemática, em Pedagogia, em Psicologia, em Expressão Gráfica, entre outras áreas.

Neste artigo, apresentamos e discutimos o cenário apresentado no conjunto de trabalhos por eixo temático, apontando a filiação institucional dos autores e suas formações acadêmicas, bem como uma síntese dos objetivos, sujeitos envolvidos, bases teóricas utilizadas, métodos e principais resultados.

Foram analisados todos os trabalhos aprovados para serem apresentados durante o VII EPEM, nas modalidades de comunicação científica, relato de experiência e pôster ${ }^{1}$. Nosso levantamento foi realizado a partir dos textos em sua íntegra, uma vez que uma análise apenas a partir dos resumos não possibilitava, em vários casos, o levantamento de informações que optamos em buscar nos mesmos.

Os trabalhos foram inscritos pelos autores por eixos temáticos que pudessem abarcar discussões mais específicas sobre as diferentes abordagens e os conteúdos. Assim, foram sugeridos 7 (sete) eixos temáticos: Educação Matemática na Educação Infantil e nos Anos Iniciais do Ensino Fundamental; Educação Matemática nos Anos Finais do Ensino Fundamental e no Ensino Médio; Educação Matemática no Ensino Superior; Educação Matemática na EJA, na Educação do Campo, Quilombola e Indígena; EaD, Tecnologias Digitais e Cibercultura na Educação Matemática; Formação dos Professores de Matemática e Aspectos Culturais, Sócio-históricos e Filosóficos na Educação Matemática.

\section{Resultados}

Iniciamos apresentando na Tabela 1 a quantidade de Comunicações Científicas (CC), Relatos de Experiência (RE) e Pôsteres (PO) apresentados em cada um dos eixos temáticos.

\footnotetext{
${ }^{1}$ Os trabalhos completos podem ser acessados no endereço http://epem.sbempe.com.br/anais/2017/
} 
Tabela 1- Frequência de trabalhos apresentados por tipo (CC, RE e PO) e por eixo temático

\begin{tabular}{l|c|c|c|c}
\hline \multicolumn{1}{c|}{ EIXO TEMÁTICO } & CC & RE & PO & TOTAL \\
\hline $\begin{array}{l}\text { 1. EM na Educação Infantil e nos Anos Iniciais } \\
\text { do Ensino Fundamental }\end{array}$ & 19 & 9 & 3 & 31 \\
\hline $\begin{array}{l}\text { 2. EM nos Anos Finais do Ensino Fundamental e } \\
\text { no Ensino Médio }\end{array}$ & 56 & 27 & 11 & 94 \\
\hline 3. EM no Ensino Superior & 9 & 4 & 3 & 16 \\
\hline $\begin{array}{l}\text { 4. EM na EJA, na Educação do Campo, } \\
\text { Quilombola e Indígena }\end{array}$ & 7 & 1 & 2 & 10 \\
\hline $\begin{array}{l}\text { 5. EaD, Tecnologias Digitais e Cibercultura na } \\
\text { EM }\end{array}$ & 10 & 3 & 1 & 14 \\
\hline $\begin{array}{l}\text { 6. Formação dos Professores de Matemática } \\
\text { 7. Aspectos Culturais, Sócio-históricos e }\end{array}$ & 16 & 6 & 2 & 24 \\
\hline Filosóficos na EM & 10 & - & 3 & 13 \\
\hline
\end{tabular}

A Tabela 1 indica a predominância de trabalhos no eixo Educação Matemática nos anos finais do Ensino Fundamental e no Ensino Médio evidenciando a grande participação de licenciandos ou licenciados em Matemática. O eixo dos anos iniciais teve um bom número de trabalhos apresentados, acrescido de outros que foram submetidos ao eixo formação de professores. Como era de se esperar, os grupos com temáticas mais específicas tiveram menos trabalhos apresentados, entretanto, com discussões mais focadas.

Observa-se também que a grande maioria dos trabalhos referia-se a pesquisas realizadas e apresentadas nas comunicações orais, evidenciando o papel dos professores como produtores de conhecimento e não apenas como consumidores passíveis de conhecimentos produzidos por outros, como defendem Esteban e Zaccur (2002) e Guimarães e Borba (2007).

Apresentamos e discutimos a seguir os cenários identificados em cada um dos eixos.

\section{Eixo 1: Educação Matemática na Educação Infantil e nos Anos Iniciais do Ensino Fundamental}

Para o eixo temático Educação Matemática na Educação Infantil e nos Anos Iniciais do Ensino Fundamental foram apresentados 19 (dezenove) comunicações científicas, 9 (nove) relatos de experiência e 3 (três) pôsteres.

Os autores dos textos apresentam diferentes formações (Pedagogia, Licenciatura em Matemática e Psicologia Cognitiva) e diferentes graus de formação (graduandos, graduados, mestres e doutores). A grande maioria dos trabalhos é de alunos e professores da UFPE, entretanto, foram também apresentados trabalhos da UFRPE, FAFIRE e IFPE, além de trabalhos de outros estados, como 1 (um) da UESC e 2 (dois) da UFAL. 
A grande maioria dos trabalhos (22) envolvia alunos e/ou turmas de alunos dos diferentes anos do Ensino Fundamental, porém, nenhum trabalho envolvia alunos da Educação Infantil, o que é uma carência lamentável diante da necessidade de estudos que possam contribuir com professores e alunos dessa faixa etária. Apenas 2 (dois) trabalhos envolviam professores, um envolvia um professor e seus alunos e um tinha como participante graduandos de Pedagogia. Outros 4 (quatro) envolviam análise de livros didáticos e 1 (um) dissertações e teses referente ao letramento matemático, alfabetização matemática ou numeramento.

Em relação aos eixos matemáticos, todos foram abordados. Em números e operações foi apresentado um trabalho sobre sistema de numeração decimal o qual ratifica que os alunos continuam valorizando que "o primeiro é quem manda" e "o tamanho depende da quantidade de algarismos". O jogo "Corrida dos Racionais" levou a um melhor desempenho dos alunos do Programa Acelera Brasil quanto à apreensão do sentido parte-todo nas representações fracionárias do número racional. Por outro lado, outro estudo evidencia que professores licenciados em Matemática apresentaram dificuldade em avaliar a resolução de um estudante dos anos iniciais do Ensino Fundamental ao resolver problemas com números racionais, confirmando o que sinalizam pesquisas anteriores.

Em relação ao trabalho com estrutura aditiva encontramos 10 (dez) trabalhos. Um deles avalia livros didáticos voltados para o ciclo de alfabetização e observa uma predominância dos problemas de comparação. Entretanto, outro trabalho descreve uma vivência na qual foi possível aos alunos compreender que a Matemática não é apenas memorização de fórmulas prontas e que ela está associada ao cotidiano no qual vivemos. Alunos ainda no $5^{\circ}$ ano ao jogarem priorizam operações de adição e subtração e fogem da divisão A utilização de jogos didáticos tem bastante influência no processo de ensino-aprendizagem de Matemática, porém, é preciso cuidado ao utilizá-los em sala de aula para que o foco esteja na finalidade didática do desenvolvimento do jogo. Cinco trabalhos envolviam experiências vivenciadas no Pibid e evidenciaram não só uma melhoria do desempenho dos alunos envolvidos, bem como incentivo tanto à formação dos estudantes quanto a dos professores envolvidos no projeto.

Referente à estrutura multiplicativa foram encontrados 8 (oito) trabalhos. A divisão por cotas foi considerada como a mais difícil, talvez porque há uma predominância nos livros didáticos de atividades que envolvem partição e os alunos demostram dificuldades em identificar a lógica dos problemas diferenciando problemas de partição e cotição. Além disso, não foram encontradas diferenças no desempenho entre alunos do $4^{\circ}$ e $5^{\circ}$ anos evidenciando que um ano de escolaridade não foi determinante para a aprendizagem. É positiva a exploração de procedimentos individuais nos livros didáticos e não só o algoritmo na resolução de 
problemas. Os resultados também sugerem que é importante considerar os enunciados dos problemas matemáticos como textos, e que existem dificuldades específicas relacionadas a este tipo de texto em particular. Em problemas que envolvem combinação, arranjo e permutação a explicitação dos invariantes não foi suficiente para gerar melhores desempenhos nos problemas. A falta de sistematização e de recursos mnemônicos para contabilizar as combinações parece ter contribuído para este resultado. A tecnologia é mais uma ferramenta que o docente pode utilizar, contudo, é preciso saber identificar qual e quando ela poderá ser auxiliar.

No eixo geometria foi encontrado apenas um trabalho o qual identificou que professoras dos anos iniciais compreendem a noção de quadrados congruentes e compreendem visualização de objetos de diferentes ângulos, mas não sabem os nomes e as funcionalidades do esquadro e do transferidor. No eixo grandezas e medidas foram encontrados dois trabalhos, sendo um envolvendo a aprendizagem do sistema monetário de forma lúdica e o outro a resolução de situações-problema que envolvem relações entre unidades usuais de medida com materiais concretos.

No eixo estatística e probabilidade foram encontrados 3 (três) trabalhos. Um deles ressalta que os alunos são capazes de levantar hipóteses e interpretar gráfico ou tabela. Habilidades de tirar conclusões a partir dos dados e utilizar vocabulário probabilístico ao se fazerem predições mostraram-se difíceis. Outro trabalho ressalta que desde o primeiro ano os alunos são capazes de localizar valores na escala e de construir gráficos. A grandeza numérica e, principalmente, a necessidade de inferir valores de uma reta numérica são os fatores mais decisivos para uma complexificação da compreensão sobre representação em gráficos. $\mathrm{O}$ terceiro trabalho evidencia que todas as crianças conseguiram elencar, ao menos, uma possibilidade e a maioria elencou três das cinco possibilidades de soma 8 ao jogarem dois dados. A maior dificuldade observada foi a ausência de percepção de que números iguais em dois dados de cores diferentes resulta em possibilidades distintas.

Envolvendo álgebra teve um trabalho com graduandos de Pedagogia o qual revela que os discentes apresentam dificuldade em resolver problemas de partilha. Um trabalho analisou livros didáticos do MEC sobre educação financeira e afirma que nos mesmos há uma preocupação em abordar a Educação Financeira (EF) de maneira que os estudantes se conscientizem da importância de conhecer, pesquisar, planejar e executar ações relacionadas à EF. Finalmente, um trabalho versou sobre a importância do planejamento e dos diversos recursos didáticos, incluindo a contação de histórias. 
O quantitativo de trabalhos é proporcional ao quantitativo de atividades propostas nos livros didáticos e nos currículos. Entretanto, é fundamental refletirmos sobre a necessidade de estudos em áreas ainda pouco investigadas como estatística e probabilidade e álgebra.

Gerard Vergnaud é o teórico mais utilizado como referência nos artigos. Outros psicólogos cognitivos também são referência, como Terezinha Nunes e Peter Bryant. Os trabalhos que referem-se à formação de professor dos anos iniciais utilizam Debora Ball e colaboradores e Shulman como base. A Teoria Antropológica do Didático é utilizada como base em dois trabalhos. Delia Lerner, Patricia Sadovsky, Carpenter e Moser e Iddo Gal são citados para artigos envolvendo o ensino aprendizagem de estruturas aditivas e estatística. Estudos de Cristiano Muniz, Gilda Guimarães e Rute Borba, pesquisadores do GT Educação Infantil e anos iniciais do Ensino Fundamental da SBEM (GT 01) também são citados como referências. Dessa forma, observa-se que os artigos estão utilizando bases internacionais e nacionais relevantes para a área.

Para realizar as investigações, diferentes metodologias foram utilizadas. A maioria dos trabalhos experimentou com os alunos algum tipo de recurso didático, envolvendo uma ou mais atividades em uma sequência didática, e analisou a aprendizagem dos mesmos. Cinco estudos envolveram entrevistas individuais com os alunos e outros dois com professoras, buscando compreender o que sabiam sobre um determinado conceito matemático. Sete artigos envolveram a proposição de testes diagnósticos individuais propostos para turmas de alunos também buscando compreender o que os mesmos sabiam sobre um determinado conceito. Apenas um artigo apresentou um estudo experimental de intervenção. Quatro estudos realizaram análise de material bibliográfico incluindo livros didáticos.

\section{Eixo 2: Educação Matemática nos Anos Finais do Ensino Fundamental e no Ensino Médio}

No eixo temático, Educação Matemática nos anos finais do Ensino Fundamental e no Ensino Médio, foram apresentados 56 (cinquenta e seis) comunicações científicas, 27 (vinte e sete) relatos de experiência e 11 (onze) pôsteres.

Observa-se o papel preponderante das universidades pelo quantitativo de trabalhos. A Universidade de Pernambuco (UPE) apresentou 43 (quarenta e três) trabalhos, seguida pela UFPE/CAA com 32 (trinta e dois) e UFPE/Recife com 23 (vinte e três) trabalhos. Foram encontrados trabalhos da UFRPE, da Universidade do Vale do São Francisco (Univasf), da Faculdade Integrada de Vitória de Santo Antão, da Autarquia Educacional de Belo Jardim (AEB), de Institutos Federais (Ipojuca, Sertão Pernambucano, Pesqueira e outros), de Escolas 
de Ensino Básico, de outras instituições federais (EESC, UESC, IFPB, UFCG, UFPB e UFPI) e, finalmente, 1 (um) da Universidad Nacional del Centro de La Provincia de Buenos Aires (UNICEN). O rol de trabalhos deste eixo temático expressa não somente a produção científica na área de Educação Matemática em Pernambuco, mas também de outros estados brasileiros e um de outro país. Esses dados corroboram para definirmos o VII Encontro Pernambucano de Educação Matemática como um espaço profícuo de discussão e compartilhamento de conhecimentos.

Em relação às comunicações científicas, caracterizam-se geralmente por apresentarem resultados de trabalhos de conclusão de curso de graduações em Matemática; recortes de dissertações concluídas ou em andamento; trabalhos finais de disciplinas cursadas tanto em Licenciatura em Matemática quanto em pós-graduações. Como nos outros eixos, os autores dos textos têm diferentes formações: Pedagogia, Licenciatura em Matemática, Psicologia Cognitiva e diferentes graus de formação (graduandos, graduados, mestres e doutores) e atuam em diferentes espaços. São professores do Ensino Superior, estudantes de graduação ou de pósgraduação. Atuam como técnicos em secretarias de educação e muitos deles como professores do Ensino Básico, aspecto bastante positivo para o diálogo entre a academia e o ensino básico.

Predominaram pesquisas qualitativas. A maioria delas, mais de 30 Comunicações Científicas, corresponde a análises documentais, envolvendo principalmente conteúdos específicos em livros didáticos à luz da Teoria Antropológica do Didático; documentos de orientação curricular; provas do Exame Nacional do Ensino Médio (Enem) e do Guia do Programa Nacional do Livro Didático (PNLD). Foram apresentadas revisões sistemáticas de textos publicados em eventos e periódicos da área de Educação Matemática sobre os seguintes temas: uso de calculadora; estudos sobre educação financeira e sobre álgebra escolar. Também um trabalho de caráter bibliográfico, descritivo, ou seja, revisão de literatura, versando sobre a utilização da codificação adequada como heurística do tipo básica, porém necessária para o método de resolução de problemas.

Quando não se tratavam de análises documentais, os sujeitos eram estudantes do Ensino Fundamental de variadas cidades pernambucanas e/ou professores. Nestes casos, os instrumentos para coleta de dados foram questionários; videografia; entrevistas e predominantemente elaboração, aplicação e análise de testes diagnósticos. Destacam-se também cerca de 6 (seis) trabalhos que propuseram a análise de softwares ou de jogos, ou de seus usos no ensino, tais como o software Winplot, Jogo Vai Vem, Algeplan, Transações Financeiras, Role Playing Game (RPG). 
Apesar de vários trabalhos não apresentarem uma teoria de base, apoiaram-se em ideias de autores reconhecidos. Dentre as bases teóricas utilizadas, destaca-se o uso expressivo da Teoria Antropológica do Didático (TAD) de Yves Chevallard, utilizada em 12 das CC submetidas neste eixo temático. No entanto, várias outras teorias da linha da didática francesa subsidiaram a elaboração dos estudos, dentre elas, a noção de Contrato Didático de Guy Brousseau; a Teoria dos Registros de Representações Semióticas de Raymond Duval e a Teoria dos Campos Conceituais de Gérard Vergnaud. Além dessas, também foram utilizadas as etapas de ações mentais de Galperin; Teoria de Van-Hiele sobre pensamento geométrico e a Teoria das Representações Sociais de Serge Moscovici. Um dos trabalhos versou sobre o ensino de radiciação para alunos com deficiência visual e outro sobre a análise de transformações geométricas numa perspectiva multidisciplinar.

Como principais resultados das análises documentais destaca-se a influência de documentos oficiais nas tomadas de decisões em relação aos conteúdos que devem ser ensinados. No entanto, a análise de livros didáticos aponta fragilidades ou limitações, como por exemplo, lacunas em livros didáticos para o $9^{\circ}$ ano em relação ao ensino do conceito de área do círculo, pois há uma ênfase em tarefas de determinação do cálculo da área com a aplicação de fórmulas. Por outro lado, as pesquisas que envolvem a análise e o uso de recursos didáticos, tais como jogos e softwares, sempre apontam êxito, ou seja, o uso se recursos inovadores contribui para o ensino e a aprendizagem de temas específicos.

Em relação aos relatos de experiência, tivemos 27 trabalhos, nos quais os autores dos textos apresentam diferentes formações (Pedagogia, Licenciatura em Matemática e Psicologia Cognitiva) e diferentes graus de formação (licenciandos, graduados, especialistas, mestres e doutores). A grande maioria dos relatos (14) envolvia alunos e/ou turmas de alunos do Ensino Médio. Nove (09) trabalhos dedicados aos anos finais do Ensino Fundamental. Dois (02) trabalhos envolviam professores da Educação Básica e licenciandos em cursos de extensão universitária. Um (01) trabalho envolvia estudantes de um curso superior e apenas um (01) trabalho envolvia coordenadores da Secretaria de Educação do Estado de Pernambuco, gestores e estudantes de Pedagogia.

Em relação aos eixos matemáticos, todos foram abordados. Mas existe uma predominância em trabalhos que envolvem geometria e de forma minoritária o eixo de estatística, probabilidade e combinatória.

A maioria dos trabalhos tem por objetivo relatar propostas metodológicas alternativas para o processo de ensino e aprendizagem da Matemática, seja por meio do uso de software Geogebra ou QR CODE, seja por jogos, dobraduras, tangram, música, geoplano e uso de 
calculadoras. Também tivemos relatos da experiência com o Pibid, Estágios Supervisionados, curso de extensão, vivências de componentes curriculares, feiras de Matemática, competições e seminários.

Predominaram pesquisas qualitativas (23), nas quais temos sequências de atividades envolvendo softwares educativos, resolução de problema, uso de jogos, dobradura, grupo interativos de Matemática e formação do professor em serviço. Temos nesse cenário pesquisas diagnósticas e experimentais.

Como principais resultados dos relatos de experiências destacam-se aqueles cujo sujeito de pesquisa era estudante, pois ficou evidente que diante de sequências de atividades, em que a metodologia empregada é dinâmica e atrativa, eles tendem a participar com mais efetividade, demonstram cooperação para trabalhar em equipe e apresentam rendimentos melhores. No entanto, também se percebem lacunas conceituais, principalmente em conceitos geométricos e algébricos por parte desses estudantes. Da mesma forma, nas pesquisas que utilizaram a tecnologia como ferramenta metodológica percebeu-se que os softwares utilizados proporcionam melhor entendimento do conceito em estudo e os alunos apresentam maior interesse nas discussões relativas ao assunto.

Os autores avaliam como positivas, para a formação inicial do professor, experiências desenvolvidas em Estágios Supervisionados, Feiras e Competições de Matemática e Seminários, uma vez que colocam na prática toda a teoria discutida na universidade. Todos os autores avaliam que as sequências de atividades foram bastante satisfatórias para o desenvolvimento da aprendizagem dos sujeitos envolvidos.

Assim, os trabalhos apresentados podem orientar professores a diferentes práticas de ensino que poderão ser exitosas.

Da mesma forma, na maioria dos pôsteres submetidos neste eixo foram relatadas propostas de sequências didáticas envolvendo a utilização de recursos didáticos ou análise desta utilização em diferentes espaços: salas de aulas, laboratórios de Matemática e até feiras de Matemática realizadas em escolas do ensino básico, nas quais se obteve êxito de aprendizagem. A motivação principal, de acordo com vários autores dos pôsteres, foi o desafio constante de superar práticas de ensino antigas e buscar uma nova metodologia que alcance os estudantes de modo mais uniforme, motivando-os e desenvolvendo uma relação positiva com a Matemática. Dentre os onze pôsteres apresentados, 5 deles referiam-se a trabalhos desenvolvidos por estudantes bolsistas do Pibid.

Dentre os recursos didáticos citados nos pôsteres destacamos o Triângulo de Siepirnski, o tangram para ensinar frações no $6^{\circ}$ ano do Ensino Fundamental; origami; Jogo Perdas e 
Ganhos e Webquest como recurso para ensinar matrizes no segundo ano do Ensino Médio; além de instrumentos para desenho geométrico. Novamente poucos trabalhos apresentavam a base teórica sob a qual se apoiaram.

\section{Eixo 3: Educação Matemática no Ensino Superior}

No eixo temático Educação Matemática no Ensino Superior foram apresentados 09 (nove) comunicações científicas, 04 (quatro) relatos de experiência e 03 (três) pôsteres. Os autores dos trabalhos eram estudantes de graduação, pós-graduação, mestres e doutores da UFPE e UPE, UFRPE, UESB, UNEB e Autarquia do Ensino Superior de Garanhuns.

Os autores tinham formação em Licenciatura em Matemática, Expressão Gráfica e Engenharia Civil, com diferentes graus (licenciandos, mestres e doutores).

As comunicações científicas caracterizam-se geralmente por apresentarem resultados de trabalhos de iniciação científica e conclusão de curso de Licenciatura em Matemática ou recorte de tese em andamento. Dessas, quatro (04) são análises documentais; duas (02) são estudos de casos e três (03) experimentais-diagnósticas.

As pesquisas do tipo análise documental versavam sobre os conteúdos de letramento estatístico nos periódicos da Capes, incongruência da trombeta de Torriceli em livros de cálculo diferencial e integral, formação para o ensino da Matemática nos cursos de Pedagogia a partir de documentos institucionais e publicações sobre a Teoria Antropológica do Didático em anais de eventos e revistas científicas de Educação Matemática.

Outras pesquisas investigaram, a partir de questionários, os conhecimentos e a utilização de softwares matemáticos na formação inicial de professores de Matemática, dificuldades dos discentes na disciplina de Cálculo Diferencial e Integral I. Outras com caráter experimentaldiagnóstica investigaram atividades envolvendo congruência de triângulos, o GeoGebra no estudo dos Poliedros de Platão e a compreensão de média aritmética.

Em relação aos eixos matemáticos, nem todos foram abordados. Existe uma predominância em trabalhos que envolvem geometria. Apesar de vários trabalhos não apresentarem uma teoria de base, apoiaram-se em ideias de Gal, Chick e Pierce, Chevallard, Duval, entre outros.

Nesse eixo foi destacada a expansão de trabalhos relativos à Teoria Antropológica do Didático (TAD) entre os anos de 2006 a 2016, a baixa carga horária da formação Matemática do Pedagogo, poucos estudos sobre formação inicial dos professores de Matemática em relação à estatística, a inserção de softwares matemáticos na graduação acontecendo de forma rápida, mas sem um aprofundamento, o trabalho em equipe mais uma vez é ressaltado como auxiliar 
na aprendizagem, licenciandos de Matemática que ainda apresentam dificuldades com funções quadráticas.

Formas de tornar a aprendizagem mais eficiente e atrativa foram experimentadas como, por exemplo, a excursão didática, o uso de softwares e jogos matemáticos. Dois trabalhos evidenciam como a monitoria proporcionou diversas vivências que acrescentaram reflexões importantes acerca da prática docente e que a confecção dos modelos didáticos confirmou que as modificações no contexto educativo, no que diz respeito às metodologias utilizadas no âmbito escolar, podem ser bastante eficazes.

\section{Eixo 4: Educação Matemática na Educação de Jovens e Adultos, na Educação do Campo, Quilombola e Indígena}

No eixo temático Educação Matemática na Educação de Jovens e Adultos, na Educação do Campo, Quilombola e Indígena foram apresentados 07 (sete) comunicações científicas, 01 (um) relato de experiência e 02 (dois) pôsteres. Predominaram pesquisas qualitativas, nas quais três (03) são análises documentais; seis (06) pesquisas diagnósticas e um (01) experimental. A maioria dos autores dos textos tem Licenciatura em Matemática e diferentes graus de formação (especialistas, mestres e doutores).

Os autores pertenciam a diferentes instituições como a UFPE, UPE, IFPE, UFCG, professores das Prefeituras de Camaragibe, Igarassu e Recife. Nesse eixo, a maioria dos trabalhos é destinada à Educação de Jovens e Adultos (EJA) e à Educação do Campo e de forma minoritária à Educação Quilombola. Não identificamos trabalhos voltados para a Educação Indígena.

Em relação às comunicações científicas, temos cinco (05) pesquisas diagnósticas que buscaram investigar conhecimentos matemáticos de estudantes da EJA em diferentes conceitos (Estatística, Probabilidade, Combinatória e Porcentagem, Estruturas Multiplicativas e Divisão) e a compreensão de professores de escolas do Campo em relação à interpretação de gráficos.

Apesar dos trabalhos não terem uma base teórica, apoiaram-se em ideias de autores reconhecidos que discutem a formação de professores, como Charlot, D’Ambrósio, Gal, Caldart e Nunes e Bryant.

Em relação aos resultados obtidos nas pesquisas que envolvem docentes, os autores apontam que os professores apesar de trabalharem em escolas localizadas em áreas campesinas não sabem sobre a proposta da Educação do Campo. Além disso, 46\% (quarenta e seis por cento) dos educadores/as camponeses, de um determinado município pernambucano, não 
possuem a formação recomendada pela Lei de Diretrizes e Bases - LDB 9394/96. Os professores do Campo apresentam dificuldades em interpretar gráficos, da mesma forma que discentes de EJA apresentam dificuldades em resolver problemas inversos na divisão e têm um baixo desempenho na resolução de problemas de Estatística, Probabilidade, Combinatória e Porcentagem.

Foi realizado um levantamento de pesquisas relacionadas às trajetórias escolares de estudantes quilombolas relacionadas com a Educação Matemática no banco de dados do Scielo e portal da Capes. Como resultados, os autores destacam a relevância da contextualização do ensino de Matemática com as situações cotidianas dos alunos quilombolas, para que eles se sintam cada vez mais participativos e reconhecidos em suas especificidades, buscando, assim, tornar o ensino e as práticas escolares com sentido para esses estudantes.

Uma pesquisa analisa o uso de malha quadriculada no livro didático utilizado na rede estadual de ensino de Pernambuco/EJA, outra apresenta uma experiência realizada com professores que lecionam nas fases iniciais da EJA articulando Língua Portuguesa e Matemática e, finalmente, um estudo que descreve o conhecimento matemático de um adulto nordestino, analfabeto, comerciante de frutas e legumes, demonstrando o que afirmavam Carraher, Carraher e Schliemann (1988).

Foram relatadas também as atividades acadêmicas intrínsecas à Educação Matemática desenvolvidas na UFCG/ Campus de Sumé. Os autores utilizam os trabalhos de TCC (graduação) e monografias (especialização) defendidas no referido curso e tomam como referência o PPC do curso.

Apesar da diversidade de pesquisas, nem todos os campos da Matemática foram abordados, como a álgebra. Constatamos que há uma carência em trabalhos que envolvem estudos com a Educação Indígena e que, ainda, aparece de forma minoritária a Educação Quilombola.

\section{Eixo 5: Educação a Distância, Tecnologias Digitais e Cibercultura na Educação Matemática}

Para o eixo temático Educação a Distância, Tecnologias Digitais e Cibercultura na Educação Matemática, foram apresentados 10 (dez) comunicações científicas, 3 (três) relatos de experiência e 1 (um) pôster. Apenas em um dos textos a autora tem formação em Pedagogia, os demais autores são graduados em Licenciatura em Matemática. Os autores pertencem a diferentes instituições de Pernambuco: UFPE, UFPE/CAA, UPE/Garanhuns, IFPE e Secretaria de Educação do Estado de Belo Jardim, além de um trabalho da UFPB e outro da UFC. Foi 
apresentado ainda um trabalho da Universidad Nacional del Centro de la Província de Buenos Aires - UNICEN.

Esses artigos têm diferentes públicos investigados. Dois trabalhos investigam professores de Matemática, dois investigam alunos de Licenciatura em Matemática, três investigam alunos do Ensino Médio e um é com alunos dos anos iniciais. Além desses, três artigos analisam softwares ou ambiente de aprendizagem e um analisa laboratórios de informática em escolas públicas.

Alguns trabalhos não apresentam teoria de base em tecnologia e os demais apresentam bases teóricas diversificadas (Trouche, Valente, Kenski, Gomes, A., Rabardel e Borba, M.).

Para realizar as investigações, 2 (dois) autores realizaram um questionário, 9 (nove) realizaram observação e 1 (um) investigou a partir do ciclo de concepção-realizaçãoexperimentação-validação. Um artigo apresentou uma revisão da literatura e outro um estudo de caso. Assim, a grande maioria investigou o uso de um software.

Os estudos concluem que a tecnologia cada vez mais vem sendo utilizada na sala de aula, embora ainda existam resistências. Os estudos evidenciam que os recursos tecnológicos, quando utilizados com a orientação devida e da forma correta, trazem ganhos no processo de ensino-aprendizagem, especialmente nas aulas de Matemática. Podemos ressaltar o software Geogebra para o estudo de funções ou a aprendizagem do conceito de prisma, o applets Java na aprendizagem de figuras geométricas e suas transformações, o software GrafEq para a compreensão de equações e representações gráficas, o software Geometria do Táxi para aprendizagem de geometria e o Software Shapari que possui importantes recursos para auxiliar o professor no processo de ensino-aprendizagem. Assim, um dos estudos conclui que a natureza da validação do conhecimento produzido na Engenharia de Softwares Educativos está situada entre a Educação e a Engenharia de Softwares em uma perspectiva de produção de conhecimento para ambas as áreas. Um dos artigos refere-se à apresentação de um protótipo de um ambiente de suporte ao ensino da Matemática, presencial ou à distância para a construção de situações de ensino.

Entretanto, um dos estudos apresentados realiza uma investigação em 50 Instituições da Educação Básica no sul da Bahia e conclui que apesar dos investimentos realizados pelo governo brasileiro em torno da informática educativa, existem muitos problemas levantados pelos professores de Matemática que inviabilizam a utilização dos laboratórios de informática. Dentre esses problemas foram levantados falta de técnicos em informática nas escolas que possam dar manutenção aos equipamentos, falta de investimento na infraestrutura de muitas escolas que têm recebido equipamentos para a instalação dos laboratórios, falta de capacitação 
de professores para lidar com as tecnologias, apoio à equipe escolar para incorporar seus projetos e auxiliá-los a utilizarem as respectivas tecnologias e a dificuldade de acesso à internet de qualidade.

\section{Eixo 6: Formação de professores que ensinam Matemática nos diversos níveis de ensino}

Para o eixo temático Formação de Professores que ensinam Matemática nos diversos níveis de ensino, foram apresentados 16 (dezesseis) comunicações científicas, 6 (seis) relatos de experiência e 2 (dois) pôsteres. Os autores dos textos têm diferentes formações: Pedagogia, Licenciatura em Matemática, Psicologia Cognitiva e Expressão Gráfica e diferentes graus de formação (graduandos, graduados, mestres e doutores). Esses pertencem a diferentes instituições de Pernambuco: UFPE, UFPE/CAA, UPE/CAA, SEEJCT/CARUARU, UFRPE, IFPE, FACIG, Secretaria de Educação do Estado, Secretaria de Educação de Olinda, Moreno e Petrolina, além de um trabalho da UFPA.

Esses artigos abordam de forma equitativa estudos com graduandos de Pedagogia ou Licenciatura em Matemática ou com professores em exercício do Ensino Fundamental e Médio. Assim, a carência de trabalhos no eixo dos anos iniciais foi suprimida pelos trabalhos apresentados aqui. Dois artigos versavam sobre o estado da arte de pesquisas nos Trabalhos de Conclusão do Curso de Licenciatura em Matemática ou nas pesquisas realizadas no agreste pernambucano.

Muitos trabalhos não apresentam teoria de base, descrevendo apenas uma sequência de atividades desenvolvidas. Entretanto, quando encontram-se bases teóricas elas são bem diversificadas (D’Ambrosio, Ball, Thames e Phelps, Tardif, Vergnaud, entre outros).

Em relação aos eixos matemáticos, observamos trabalhos referentes à aprendizagem de alunos sobre geometria, estrutura multiplicativa, combinatória e trigonometria. Outros trabalhos refletem sobre os diferentes enfoques de formação de professor, incluindo as novas tecnologias e a formação complementar do Pibid. Para realizar as investigações, diferentes metodologias foram utilizadas: observação de aula, entrevistas, questionários, teste diagnóstico e fórum de discussão. Porém, a metodologia mais utilizada foi o desenvolvimento de uma sequência de atividades desenvolvida por graduandos ou professores em exercício para formação de alunos do ensino básico ou graduandos.

A maioria dos estudos tem se preocupado com as discussões em torno das ações de formação inicial ou continuada para os professores que ensinam Matemática nos diversos níveis de ensino. Assim, é preciso pensar sobre as fragilidades nas constituições dos cursos que trabalham com o ensino de Matemática. Isso se explica uma vez que têm sido observadas 
carências de conhecimento do professor que muitas vezes sabem apenas os conhecimentos sobre o conteúdo comum (BALL; THAMES; PHELPS, 2008), o que é insuficiente para o ensino. Os próprios professores reconhecem suas limitações conceituais, didáticas ou procedimentais em relação ao ensino da Matemática. Entretanto, manifestam o desejo e a disposição de ter uma relação mais próxima dos saberes matemáticos que ensinam. Por outro lado, são ressaltados o empenho e o compromisso que os professores têm com o ensino de Matemática e a aprendizagem dos alunos.

Assim, é fundamental criar e divulgar metodologias e ferramentas que facilitem o ensino e a aprendizagem de Matemática, não esquecendo que trabalhar com metodologias diferentes contribui para o ensino-aprendizagem dos alunos e, também, para a formação do professor. A tecnologia, como o uso do Geogebra para o ensino de geometria, materiais manipuláveis ou a utilização de jogos, continua sendo levantada como auxiliar importante para o ensino. Por outro lado, analisar protocolos foi levantado, também, como uma rica experiência para a formação acerca do aprofundamento do conhecimento do conteúdo, além da elaboração de problemas contextualizados visando à discussão acerca do conceito no processo de formação inicial e continuada do professor. A produção de conhecimentos matemáticos de forma colaborativa é fundamental.

Dois artigos referem-se ao Programa Institucional de Bolsas de Iniciação à Docência (Pibid). Esse Programa se mostrou como um fator determinante na formação de vários licenciandos, contribuindo para a valorização dos educadores e para o aumento da qualidade da formação inicial de professores em integração com a Educação Básica, uma vez que passaram a explorar e problematizar os conceitos matemáticos, bem como formas significativas de aprendizagem destes.

\section{Eixo 7: Aspectos Culturais, Sócio-históricos e Filosóficos na Educação Matemática}

Para o eixo temático Aspectos Culturais, Sócio-históricos e Filosóficos na Educação Matemática, foram apresentados 10 (dez) comunicações científicas e 03 (três) pôsteres. Os autores dos textos são estudantes da graduação em Licenciatura em Matemática ou pósgraduação, mestres e doutores. Esses pertencem a diferentes instituições UNEB, UESB, UFPE, UPE, UFRPE, IFPE e UEMA.

Nesse eixo, tivemos trabalhos voltados para a EtnoMatemática, História da Matemática, Modelagem, relação interpessoal e Matemática Crítica. 
Em relação às comunicações científicas, predominaram pesquisas qualitativas, das quais cinco (05) do tipo análise documental, sendo uma bibliográfica e quatro de revisão sistemática. Tivemos, ainda, uma proposta de sequência de atividade para alunos do Ensino Médio, com enfoque na História da Matemática, um estudo de caso e três pesquisas do tipo diagnóstico.

As pesquisas do tipo análise documental apresentavam diversos objetivos, tais como demonstrar a importância do Programa EtnoMatemática diante de uma análise de diversas perspectivas; realizar um levantamento de publicações sobre EtnoMatemática no contexto profissional, com trabalhadores de baixa escolaridade, nos últimos cinco eventos do Encontro Nacional de Educação Matemática; analisar as temáticas das comunicações científicas versando sobre Modelagem Matemática apresentadas no XII Encontro Nacional de Educação Matemática realizado em São Paulo (2016); apresentar uma análise textual dos trabalhos publicados sobre EtnoMatemática no XI e XII Encontro Nacional de Educação Matemática e analisar as atividades do livro didático direcionadas para os objetos de estudo da Estatística, na perspectiva da Educação Matemática Crítica.

Os trabalhos voltados para EtnoMatemática tiveram como inspiração teórica as ideias de Ubiratan D’Ambrósio e Knijnik. Em relação à Modelagem Matemática, os autores citaram Bassanezi, Kluber e Burak entre outros. E, no trabalho voltado para a Matemática Crítica, tomou-se como aporte teórico Skovsmose.

Os resultados das pesquisas cujo objeto de estudo era a EtnoMatemática argumentam que se o programa for bem compreendido pelos professores pode contribuir para melhorias no ensino da Matemática. A maioria das publicações sobre EtnoMatemática se relaciona à vivência de trabalhadores rurais em detrimento de estudos com trabalhadores em áreas urbanas. Em relação às pesquisas com Modelagem Matemática, foram encontradas 30 publicações nas comunicações científicas do XII ENEM envolvendo todos os níveis de ensino e formação continuada de professores. Na pesquisa, cuja perspectiva era a Matemática Crítica, os autores constataram que o paradigma do exercício ainda predomina dentre as atividades matemáticas, contribuindo para uma mera transmissão passiva de conhecimento.

Os autores desse eixo ainda ressaltam que os trabalhadores (pedreiro/carpinteiro e agricultores) aprenderam os conhecimentos matemáticos por transmissão oral ou por observação. Esses resolvem problemas sem dificuldades e por meio do cálculo mental, apesar de conhecer os aparatos tecnológicos considerando que as medições de terras em terrenos onde a topografia se apresenta de maneira irregular, a braça alcança toda a encosta aproveitando ao máximo todo terreno; que cambistas só conseguiam responder problemas de combinatória em situação do jogo do bicho e quando docentes e gestores trabalham juntos contribuem de forma 
significativa para o desenvolvimento do processo ensino aprendizagem. Da mesma forma, o uso de atividades que favoreçam a interatividade entre o sujeito e o seu objeto de conhecimento faz com que a participação efetiva do aluno na construção de seu conhecimento em sala de aula aconteça. Além disso, a História da Matemática pode ser uma grande aliada no ensino, pois ao demonstrar o método histórico de multiplicação egípcio em sala de aula, os autores perceberam que trabalhar utilizando esses métodos pode servir como uma importante ferramenta de ensinoaprendizagem, principalmente nos anos iniciais, pois motiva os alunos a fazerem suas descobertas. Finalmente, licenciandos em Matemática da UPE afirmam que a metodologia de ensino tradicional de Matemática não é suficiente para formar cidadãos críticos e reflexivos, mas eles não conseguem identificar propostas pedagógicas, a serem utilizadas em sala de aula, que consideram a realidade sociocultural dos estudantes.

\section{Considerações Finais}

Este trabalho se propôs a analisar a produção científica apresentada no VII Encontro Pernambucano de Educação Matemática, evidenciando o cenário atual e os desafios que ainda precisam ser enfrentados pela Educação Matemática. Para isso, realizamos um estado da arte com as comunicações científicas, relatos de experiências e pôsteres disponibilizados nos Anais do VII EPEM.

Constatamos um cenário promissor para Educação Matemática em Pernambuco, uma vez que houve um grande envolvimento de graduandos de diversas licenciaturas, entre elas Pedagogia, Matemática, Expressão Gráfica, Psicologia, o que pode sinalizar uma tendência de crescimento nos próximos anos de educadores matemáticos. Também destacamos positivamente a participação de professores que atuam na Escola Básica, caracterizando a relação entre a pesquisa e a sala de aula. Do mesmo modo, também constatamos a participação de pesquisadores doutores ou doutorandos, mestres ou mestrandos de diversos programas de pós graduação em Educação Matemática, mostrando o vigor da pesquisa nesta área.

Por outro lado, nenhum trabalho envolvia estudantes da Educação Infantil, o que configura um desafio para os próximos eventos, ou seja, oportunizar estudos que possam contribuir com professores e alunos desse nível de ensino. Há uma carência de trabalhos que envolvem estudos com a Educação Indígena e Quilombola, o que configura um novo desafio de desenvolver estudos que investiguem práticas de ensino em Matemática voltadas para esse público. 
Outro desafio é refletir sobre a necessidade de estudos em áreas ainda pouco investigadas, como, por exemplo, álgebra, estatística e probabilidade em diversos níveis de ensino.

Foram encontrados vários trabalhos com análise de softwares ou de jogos e seus usos no ensino, os quais sempre apontam êxito na aprendizagem. Fiorentini, Passos e Lima (2016) também encontraram muitos trabalhos que utilizam observações e registros de aulas realizadas nas escolas. Esses artigos, em geral, são relatos de experiência que podem orientar professores a diferentes práticas de ensino que poderão ser exitosas. Assim, parece que a ausência de trabalhos relacionados à prática do professor encontrada por Fiorentini (2002) e Godino, Carrillo, Castro, Lacasta, Muñoz-Catalán e Wilhelmi (2012) vem sendo superada, uma vez que observamos uma grande quantidade de trabalhos dessa natureza.

Entretanto, existem muitos problemas levantados pelos professores de Matemática que inviabilizam a utilização das tecnologias, como manutenção dos equipamentos, formação dos professores para lidar com as tecnologias e a dificuldade de acesso à internet, que precisam ser superados para que esses recursos possam ser utilizados de forma mais abrangente.

Observamos que predominaram pesquisas qualitativas, sendo a maioria de análises documentais, envolvendo principalmente conteúdos específicos em livros didáticos, orientações curriculares e exames de larga escala. Fiorentini, Passos e Lima (2016) já haviam ressaltado, em relação às dissertações e teses, a grande quantidade de estudos qualitativos na região nordeste.

Finalmente, encontramos variadas bases teóricas e metodológicas, o que demonstra a pluralidade da área e análises a partir de diferentes pontos de vista. Porém, continua a existir uma ausência de explicitação das mesmas em muitos artigos, como já levantaram Godino, Carrillo, Castro, Lacasta, Muñoz-Catalán e Wilhelmi (2012), Guimarães e Pessoa (2014) e Fiorentini, Passos e Lima (2016). Por outro lado, existem artigos que apresentam diferentes bases teóricas ou metodologias que precisariam ser mais refletidas, uma vez que as articulações metodológicas devem ser vistas em termos de coerência com o solo teórico da pesquisa, como argumenta Barbosa (2017).

Portanto, diante deste cenário que se mostrou promissor, porém bastante desafiador, a Sociedade Brasileira de Educação Matemática, representada por aqueles que se comprometem com a realização de uma Educação Matemática qualificada, e, especialmente, por aqueles que participaram do VII Encontro Pernambucano de Educação Matemática, deve buscar estratégias para reforçar ainda mais a importância deste caminho de mão dupla: da investigação à sala de aula e da sala de aula para a investigação. 


\section{REFERÊNCIAS}

BALL, D.; THAMES, M. H.; PHELPS, G. Content Knowledge for Teaching: what makes it special? Journal of teacher educacion, USA, v. 59, n. 5, p. 389-407, 2008.

BARBOSA, J. Abordagens teóricas e metodológicas na Educação Matemática: aproximações e distanciamentos. Anais da 38 ${ }^{\mathbf{a}}$ Reunião Nacional da ANPEd, São Luís/MA, 2017.

CARRAHER, T.; CARRAHER, D.; SCHLIEMANN, A. Na vida dez, na escola zero. São Paulo: Cortez, 1988.

ESTEBAN, M.; ZACCUR, E. A pesquisa como eixo de formação docente. Professorapesquisadora. Uma práxis em construção. Rio de Janeiro: DP\&A, 2002.

FERREIRA, N. As pesquisas denominadas "Estado da arte". Educação \& Sociedade, Campinas, ano XXIII, ${ }^{\circ}$ 79, Agosto, 2002.

FIORENTINI, D. Mapeamento e balanço dos trabalhos do GT-19 (Educação Matemática) no período de 1998 a 2001. Anais da 25 ${ }^{\mathbf{a}}$ Reunião da Anped. Caxambu, 2002.

FIORENTINI, D.; PASSOS, C. L. B.; LIMA, R. C. R. de (orgs.). Mapeamento da pesquisa acadêmica brasileira sobre o professor que ensina Matemática: período 2001 - 2012. Campinas, SP: Faculdade de Educação da Unicamp, 2016.

GODINO, J.; CARRILLO, J.; CASTRO, W.; LACASTA, E.; MUÑOZ-CATALÁN, C.; WILHELMI, M. Métodos de investigación en las ponencias y comunicaciones presentadas en los simposios de la SEIEM. Avances de Investigación en Educación Matemática, v. 2, p. 29-52, 2012.

GUIMARÃES, G.; PESSOA, C. Estado da Arte do GT de Educação Matemática: EPENN 2007, 2009 e 2011. In: GOMES, A. M.; FERRAZ, T. Perspectivas: Pesquisas em Educação nas Regiões Norte e Nordeste - Balanço e Perspectivas. Recife: Editora da UFPE, 2014. p. 391-402.

GUIMARÃES, G.; BORBA, R. Professores e graduandos de Pedagogia valorizam e vivenciam processos investigativos? Revista Tópicos Educacionais, Recife, v. 17 (1/3), Centro de Educação da UFPE, 2007.

NORONHA, D. P.; FERREIRA, S. M. S. P. Revisões de literatura. In: CAMPELLO, B. S. V. C.; CENDÓN, B. V.; KREMER, J. M. (Orgs.). Fontes de informação para pesquisadores e profissionais. Belo Horizonte: UFMG, 2000.

RICH, A. When We Dead Awaken: Writing as Re-Vision. College English, Urbana, v. 34, n. 1, p. 18-30, 1972. 
VOSGERAU, D. S. A. R.; ROMANOWSKI, J. P. Estudos de revisão: implicações conceituais e metodológicas. Revista Diálogo Educacional, Curitiba, v. 14, n. 41, p. 165 $189,2014$. 